\title{
Review on Existing Fire Monitoring and Extinguishing Systems In Various Domain Verticals
}

\author{
D.O.I - 10.51201/Jusst12656 \\ http://doi.org/10.51201/Jusst12656 \\ Naina Mahile1, Dipali Chakole2, Nikita Kotangale3, Mitali Charde4, Triveni Pendam5, \\ Supriya Sawwashere6 \\ Dept of Computer Science and Engineering, JD college of engineering and management Nagpur.
}

\begin{abstract}
:
Fire is one of the most frequently occurring and destructive disasters and it is extremely serious hazard to people life safety. It is an undesirable mishap which emits heat, smoke or flame and gets converted in the huge fire. Over the last few years, the demand of fire safety systems has taken a drastic increase due to the public awareness. The main motivation of this paper is to review the existing fire monitoring and extinguishing systems in various verticals of the working domains. Also it gives the brief about the design of automatic sensor based fire alerts, and extinguishing system inferring the Artificial Intelligence and machine learning. The system will be able to locate the victim location and intimation to various stations to be included in the fire control the fire exposures. By implementing the proposed system in a particular area, it is possible to spot the fire within small course of time, and extinguish it without risking human lives.
\end{abstract}

Keywords: We would like to encourage you to list your keywords in this section

\section{Introduction:}

Fire may be a very useful gizmo in human life, it's the foremost common serious hazard that may have a awfully negative effect on humans Fire is one in every of the foremost frequently occurring and destructive disasters and it's extremely serious hazard to peoples life safety. When a hearth occurs, extinguishing a fireplace early is incredibly important. Therefore, Also, fire extinguishers are the primary line of defence and a valuable means of egress during emergency during this paper, we proposed a realtime monitoring device and warning system. The target of this paper is to acknowledge the pressure of fireside extinguisher in smart phone applications Fire extinguishers are vital equipment to stop the massive fires in emergency situations and minimizing the mishaps. This system can detect abnormal and dangerous situation and notify us. This paper establishes the necessities, conditions, design problems, solutions and future plans for the fire fighting system. First, we design a system with extinguisher this technique includes structure, avoidance obstacle, software development system, fire detection.. We implement some malicious program to detect only fire. In India there are numerous accidents will occur because of fire As a result, automatically detects the fireplace, and sends an tuned in to the user. During this study, we made improvements to the current system. As a result, it became possible to detect a good range of fireplace extinguishing. If an automatic system is created for fire accidents, then we will have an early warning system. this can be very effective in a very fire accident in industries and residential areas where the fireplace possibilities For this sends the situation to extinguisher department that would quickly and efficiently find the hearth and suppress it. Effective monitoring, high speed recognition, and 
extinguishing of fireplace are problems to be proscribed immediately. the automated android application is intended to avoid further spreading of the fireplace that might cause possible human causalities or damage to property and it will help the fireplace fighters to try to their job effectively.

\section{Literature review :}

The authors[1] developed the prototype for a fireplace extinguishing robot with a fireplace detecting mechanism that may detect, locate and extinguish fire initially sign of smoke, with a SMS Capability. They have analysed the Delay between the transfer messages from landholder about detection of fireplace and receiving of SMS of the target system. In paper [2], the authors developed a system which will be able to detect a victim place automatically with the help of image processing and the fire will be controlled using web browser. The designed system was very cheap and less space consuming. A real time fire testing platform was introduced in paper [3], for the kitchens. The system was able to detect oil pan fire, kitchen flue fire and cabinet fire tests. The fire was detected through the change and development of temperature, smoke and fire situation. It was very difficult to extinguish oil fire and use of water based devices and dry powder extinguisher was mandatory.

The development of a multiple sensors based asphyxiate robot was proposed in [4]. The developed extinguisher robot was operated in multiple modes using the DTMF and Bluetooth remote additionally as GSM and GPS technology. Robot was designed with three styles of sensors like a flame sensor, smoke sensor, and temperature sensor whereas one or maximum two varieties of sensors was familiarized to implement such quite robot. They analysed that the robot won't stop spraying water until all three sensors respond negatively in order to get away. It could be a common nature of fireside that it can activate anytime if a flammable source is accessible within the incident spot.

The authors [5] developed the system provided at suction ducts at each partition of the train compartment along with $\mathrm{CO} 2$ device for fire suppression. If the temperature goes above $80^{\circ} \mathrm{C}$, then the Arduino gives the command to enable buzzer, alerting signal to GSM network, extinguisher. The system was developed with the help of 8 pairs of temperature detectors positioned at the underside of every train cabin windows and a smoke detector positioned at the doorway, which was connected to the pump which continuously sucks the compartment air and offers it to the gas sensor. Signals from the 8 sensors were constantly monitored via Arduino and so the outputs are activated if the harm is detected.

The authors [6] have given a short overview on latest technological improvements utilized within the hearth services. The authors provided four significant fire fighting inventions as Cold extinguisher, sonic device, Drones and Thermal Imaging Camera and analyzed their characteristics within the fire fighting operations. Fire services technological advancements can decrease the danger of injuries and fatalities. In the research [7] the URL address of affected location used to share with fireside control office by GSM module through Google Map to trace the affected location and timely operation is made possible. Presented system was more efficient, robust and low cost comparatively.

An Arduino based automatic fire alarm provider with extinguishing device has been proposed for fire protection [8]. The thermal model of a house was built where smoke detector and temperature sensor assist the flame sensor, which activates above the conditioned artificial environment maintained at $27^{\circ} \mathrm{C}$. The author [9] presented the implementation of dual mode firefighting robot. The proposed fire 
extinguishing robot works in either automatic or manual mode. The operation of robot is monitored and controlled by Arduino UNO microcontroller. The authors [10] developed the robotic vehicle for spraying of water within the fireplace controlled by voice command. The communication between the vehicle and humans were established through the NODE MCU and ARDUINO. This Robotic vehicle was involved in saving the people and extinguishing the hearth where fire fighters don't seem to be able to enter into the hearth accidental area. The vehicle could control from anywhere by adding GPS module to the robotic vehicle. $\mathrm{A} \mathrm{CO}_{2}$ Extinguisher was mounted to make the robotic vehicle that becomes a sturdy extinguisher. In paper [11], study of the discharge characteristics of the extinguishing agent from device with different configurations of nozzles in a very limited space has been presented,in which a fire extinguishing experiment platform was established. for various convergent nozzles, the larger the taper angle, the upper the diffusion concentration, and thus the higher the discharge effect.

The authors [12] introduced an ultra-fine water mist extinguisher, and studied on total flooding extinguishing test of ultra-fine water mist extinguishing combustion of paper in confined space with the dimensions of $2.4 \mathrm{~m} \times 2.4 \mathrm{~m} \times 3.5 \mathrm{~m}$. Using the ultra-fine water mist extinguisher in total flooding extinguishing test in confined space to position out paper burning, made up for the deficiency of the related research which only experiment in small space. The authors [13]introduced automatic Fire Extinguishing Hardware based model able to work in fireside accident during fire accident. The robot has been developed which features to manoeuvre within the direction with a regard to the fireside intensity. In the article [14], had a development of fireside extinguishing simulation. They analysedthe features of complex adaptive systems theory and simulation of fireplace extinguishing system. The authors [15] proposed anautomated vision system for rapid fire onset detection. to stop the born of a mishap, a system constituted by two firewire cameras and a laptop, that manages images from the cameras and remotely controls a fireplace extinguisher, was designed and realized. This technique was helpful for on-line monitoring of possible starting fire in closed environment without the necessity of retrofitting an area to put in a commonly used system.

Safetyat transformers and electrical substations of the economic facilities, was an important aspect of minimizing the plant shutdown periods in addition as workers safety [16]. In this event of fireside at a substation or transformer there could be casualties' even worse, fatalities. The legislation burning detection and extinguishing systems for indoor and outdoor transformer, substation and switchgear rooms in Turkey was receptive interpretation. The authors [17] presented the planning methodology and implementation of a coffee cost autonomous robot prototype which detect presence of fireside from its surroundings and take necessary measure to extinguish it. The employed system autonomously detects fire, moves toward it and extinguishes the hearth.

As a summary, it can be concluded that the fire is generated by heating elements and the fire extinguishing robots can help to minimize the mishaps faced because of fire. Fire extinguishers are very important equipment to prevent the large fires in emergency situations and minimizing the mishaps.

\section{Problem Statement :}

The older fire extinguishing methodologies were risky to apply and time consuming, As the mishap was to be informed to the fire extinguishing department and the further processing up to loss recoveries. As the world is growing towards the automation of many processes using IOT technologies, fire related 
mishaps are also needed to be alarmed by sensing and transmitting the victim information to the destination from where necessary action will be taken by extinguishing unit.

The main aim of the proposed system is to design a low cost and simple wireless Fire protection system against fire outbreak and provide an early notification system to avoid serious damaged due to this type of hazards. Also, the system should be able to react in emergency situation in order to minimize the losses of lives and assets.

\section{Proposed Methodology :}

The proposed system can detect abnormal and dangerous situation and notify us. This paper establishes the necessities, conditions, design problems, solutions and future plans for the firefighting system. First, we design a system with extinguisher. This method includes structure, avoidance obstacle, software development system, fire detection et al. We implement some computer virus to detect only fire. We implement the system and if fire accident is true, the hearth extinguisher system can be told the fireplace source by the proposed method and move to fireplace source to fight the fireplace using extinguisher. Device affects on the lives of individuals and other domestic and loss. Smoke sensor:Automatic notification of emergency responders and safety. Monoxide is an odorless and colorless gas, which suggests you will not even bear in mind a controversy is present unless your alarm sounds. Buzzer :Easily compatible, uses lesser energy, high and effective piezo buzzer sound. A buzzer with an occasional power consumption rate is economical since it'll only require less amount of power to operate. High instantaneous sound pressure, Large voltage usage range, Small in size, good frequency response.

- Wifi module:Wifi doesn't require a physical cable to attach. Wifi is sweet for device that doesn't have the aptitude of a wired connection.

- Aurdino kit:Development of automation system and projects supported code-based control.

- Android mobile: Multitasking and straightforward to handle.

- Fire sensor:Hydrogen stations,Industrial heating, Fire detection, Fire alarm,Industrial gas, etc.

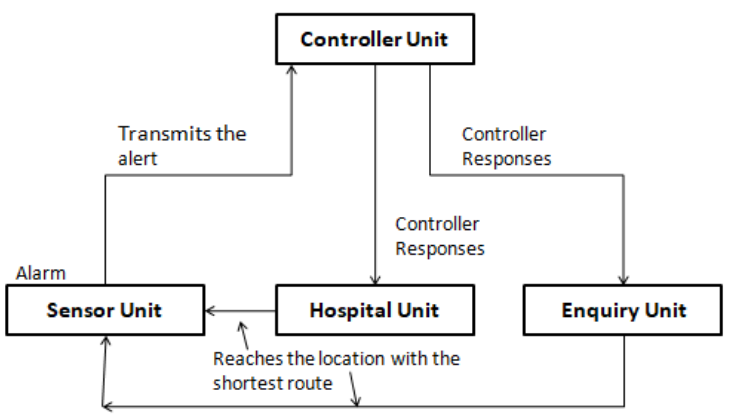

Figure 1. System Design: Alert Module 
The proposed automated system will be implemented for automatic intimation of fireside accident with its location, fetched by GPS system to the fireplace extinguishing officer and that they are going to the victim place by the shortest and optimized route. The proposed system are often helpful to avoid and minimized the damages and loss of lives of individuals. The victim place are notify to station house to avoid the mishaps being happened within the nearby crowd. this technique can detect abnormal and dangerous situation and notify us this paper establishes the necessities, conditions, design problems, solutions and future plans for the firefighting system. First, we design a system with extinguisher this method includes structure, avoidance obstacle, software development system, fire detection et al. We implement some computer virus to detect only fire. We implement the system and if fire accident is true, the fireplace extinguisher system can be told the hearth source by the proposed method and move to fireplace source to fight the fireplace using extinguisher. Device affects on the lives of individuals and other domestic and loss.

\section{References :}

[1]Undug, J., Arabiran, M.P, Frades, J.R. Mazo, J. and Teogangco, M." Fire Locator, Detector and Extinguisher Robot with SMS Capability", 8th IEEE International Conference Humanoid, Nanotechnology, Information Technology, 2015,pp-1-5.

[2] HayatoTakahashi ,YuhkiKitazono, Masahiko Hanada, HiromichiHanada, KanyaMizuguchi, AKinori Fujimoto, Seiichi Serikawa. "Improvement of Automatic Fire Extinguisher System for Residential Use”,3rd International Conference on Industrial Application Engineering,pp-1-4.

[3] XiaoyuanXu ,Pengfei Wang, NianhaoYu, Hongya Zhu . "Experimental Study on Kitchen Fire Accidents in Different Scenarios ",Authorized licensed use limited to: Auckland University of Technology, 2020 ,pp-1-6.

[4] Humayun Rashid, Iftekhar Uddin Ahmed, AasimUllah, MD. FahimNewaz, MohammadSijanurRahaman Robin, S M Taslim Reza. "Multiple Sensors Based Fire Extinguisher Robot Based on DTMF, Bluetooth and GSM Technology with Multiple Mode of Operation" ,International Workshop on Computational Intelligence (IWCI), 2016, pp-1-6.

[5] P.ArunMozhi Devan, G.Manisha, K.G.T.Rajarajeswari, M.Priyanga, K.Sangeetha . "FIRE SAFETY AND ALERTING SYSTEM IN RAILWAYS”, 3rd IEEE International Conference on Recent Trends in Electronics, Information \& Communication Technology (RTEICT-2018), 2018, pp-1-5.

[6] I. Vajdov, B. Mikula, E. Jencova, S. Mako. "The Innovations Improving Fire Services at Airports" , Department of Air Transport Management, Faculty of Aeronautics, Technical university, 2019 , pp-16.

[7] Sarita Gupta, AjayMudgil ,Prashant Bhardwaj, Mahendra Gupta. "Design and Development of Automatic Fire Alert System ", 8th International Conference on Computational Intelligence and Communication Networks , 2016 ,pp-1-5.

[8] Md. Rawshan Habib, Naureen Khan, Koushik Ahmed, Mahbubur Rahman Kiran, A.K.M. Asif, Mohaiminul Islam Bhuiyan, and Omar Farrok . "Quick Fire Sensing Model and Extinguishing by Using an Arduino Based Fire Protection Device" , 5th International Conference on Advances in Electrical Engineering (ICAEE), 2019,pp-1-5.

[9] JoyalRaju, JohaanVarkey Paul, Sheik Mohammed S, Georgy Abel John, Dinanath S. Nair. “ Development and Implementation of Arduino Microcontroller Based Dual Mode Fire Extinguishing 
Robot" , IEEE INTERNATIONAL CONFERENCE ON INTELLIGENT TECHNIQUES IN CONTROL, OPTIMIZATION AND SIGNAL PROCESSING ,2017,pp-1-4.

[10] R.Karthik,T.Divagar, M.Karthikeyan , D.Manoj Kumar. "Voice Operated Intelligent Fire Extinguishing Vehicle ”, 5th International Conference on Advanced Computing \& Communication Systems (ICACCS), 2019,pp-1-4.

[11] Han Zhang, Xuhai Pan, Min Hua, YiMingJiang, XinxinGuo, Hangchen Li. "Experimental study on release characteristics of the gas-liquid extinguishing agent in a confined space" , Authorized licensed use limited to: Cornell University Library, 2020,pp-1-5.

[12] De-ming ZHU, Jian-yong LIU, Yuan YU, Dong LIANG. "Experimental Study on Total Flooding Extinguishing Test by New Ultra-fine Water Mist Fire Extinguisher Extinguishing Combustion of Paper",7th International Conference on Intelligent Computation Technology and Automation, 2014,pp-1-4.

[13] B. SwethaSampath. "Automatic Fire Extinguisher Robot" , 8th International Conference on Ubiquitous Robots and Ambient Intelligence (URAI), 2011, pp-1-4.

[14] Chang Chunyuan, Ma Yan. "Simulation of Forest Fire Extinguishing Based on Complex Adaptive System Theory” , Second International Conference on Intelligent Computation Technology and Automation, 2009 , pp-1-4.

[15] A. Pesatori, M. Norgia, C. Svelto. "Automated Vision System for Rapid Fire Onset Detection" I2MTC 2009 - International Instrumentation and Measurement Technology Conference ,2009, pp-14.

[16] Ergun Sivrikaya, BülentIyigün, Murat Tekin, Mehmet FatihKivrak, ErgünCavdar, ÇağdaşDiker, OgünÖzfidan, SelahattinKucuk. "National Legislation and International Standards for Fire Detection and Protection Systems for Industrial Transformers and Substations of Industries Facilities”, 6th International Conference on Electrical and Electronics Engineering (ICEEE) , 2019 ,pp-1-7.

[17] A.Q.M. sazzadSayyed, Md. TasnimulHasan, ShakibMahmood, Abdul Rakib Hossain . "Autonomous Fire Fighter Robot Based on Image Processing", IEEE Region 10 Symposium (TENSYMP), 2019 , pp-1-5. 